\title{
BMJ Open Balance and walking after three different models of stroke rehabilitation: early supported discharge in a day unit or at home, and traditional treatment (control)
}

\author{
Bente Elisabeth Bassøe Gjelsvik, ${ }^{1,2}$ Håkon Hofstad, ${ }^{2,3}$ Tori Smedal, ${ }^{1}$ \\ Geir Egil Eide, ${ }^{4}$ Halvor Næss, ${ }^{5,6}$ Jan Sture Skouen, ${ }^{2,3}$ Bente Frisk, ${ }^{1}$ Silje Daltveit, ${ }^{1}$ \\ Liv Inger Strand ${ }^{1,2}$
}

To cite: Gjelsvik BEB, Hofstad H, Smedal T, et al. Balance and walking after three different models of stroke rehabilitation: early supported discharge in a day unit or at home, and traditional treatment (control). BMJ Open 2014;4 e004358. doi:10.1136/ bmjopen-2013-004358

- Prepublication history and additional material is available. To view please visit the journal (http://dx.doi.org/ 10.1136/bmjopen-2013004358)

Received 29 October 2013 Revised 8 April 2014 Accepted 10 April 2014

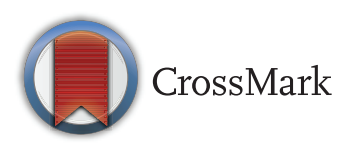

For numbered affiliations see end of article.

Correspondence to Bente Elisabeth Bassøe Gjelsvik; bente.elisabeth. bassoe.gjelsvik@helsebergen.no

\section{ABSTRACT}

Objective: To compare the effects on balance and walking of three models of stroke rehabilitation: early supported discharge with rehabilitation in a day unit or at home, and traditional uncoordinated treatment (control).

Design: Group comparison study within a randomised controlled trial.

Setting: Hospital stroke unit and primary healthcare. Participants: Inclusion criteria: a score of 2-26 on National Institutes of Health Stroke Scale, assessed with Postural Assessment Scale for Stroke (PASS), and discharge directly home from the hospital stroke unit.

Interventions: Two intervention groups were given early supported discharge with treatment in either a day unit or the patient's own home. The controls were offered traditional, uncoordinated treatment.

Outcome measures: Primary: PASS. Secondary: Trunk Impairment Scale-modified Norwegian version; timed Up-and-Go; $5 \mathrm{~m}$ timed walk; self-reports on problems with walking, balance, ADL, physical activity, pain and tiredness. The patients were tested before randomisation and 3 months after inclusion.

Results: From a total of 306 randomised patients, 167 were tested with PASS at baseline and discharged directly home. 105 were retested at 3 months: mean age 69 years, 63 men, 27 patients in day unit rehabilitation, 43 in home rehabilitation and 35 in a control group. There were no group differences, either at baseline for demographic and test data or for length of stroke unit stay. At 3 months, there was no group difference in change on PASS ( $p>0.05)$. Some secondary measures tended to show better outcome for the intervention groups, that is, trunk control, median $(95 \% \mathrm{Cl})$ : day unit, 2 (0.28 to 2.31$)$; home rehabilitation, 4 ( 1.80 to 3.78 ); control, 1 (0.56 to 2.53), $p=0.044$; and for self-report on walking, $\mathrm{p}=0.021$ and $\mathrm{ADL}, \mathrm{p}=0.016$.

Conclusions: There was no difference in change between the groups for postural balance, but the secondary outcomes indicated that improvement of trunk control and walking was better in the intervention groups than in the control group.

\section{Strengths and limitations of this study}

- Use of objective and self-reported outcome measures that represent body functions and activity domains of the International Classification of Functioning, Disability and Health (ICF).

- Sample size.

- High baseline scores for primary outcome.

- Loss to follow-up.

Trial registration: This study is part of the Early Supported Discharge after Stroke in Bergen, ClinicalTrials.gov (NCT00771771).

\section{INTRODUCTION}

In the past decade, several studies that evaluate the effect of early supported discharge on short-term and long-term outcome after stroke have been published. ${ }^{1-3}$ The greatest benefits that such studies show are associated with support from a coordinated multidisciplinary team. ${ }^{4}$ Early supported discharge combined with adequate resources has been found to reduce long-term physical dependency and the need for admittance to an institution. ${ }^{1}$ However, rehabilitation models may differ, and the effectiveness of various models should be investigated.

To the best of our knowledge, the effects of early supported discharge on patients' physical capacity, defined as what a person can do in a standard environment, ${ }^{5}$ have only been examined in three studies. These show no differences in balance and walking between the groups. ${ }^{6-8}$ Two of these studies had low statistical power ${ }^{67}$ and all had small 
sample sizes. ${ }^{6-8}$ Thus, changes in physical capacity and comparisons between treatment arms do not seem to have been fully explored. It is therefore desirable to examine change in physical capacity in a larger scale study that compares the effects of various rehabilitation models.

The social and physical context for rehabilitation is considered important to patient outcome. $^{9}$ Rehabilitation provided at home allows the patient to practise in a real-life environment, which could directly enhance functioning and participation in daily life tasks. Meeting the actual needs of the patients and their families within their own homes could motivate patients more than when training takes place in an outpatient context. At the same time, rehabilitation in a centre could give more focused training on balance and walking, and enhanced training effects. ${ }^{9}$

The aim of this study was therefore to compare the effects on balance and walking of three models of stroke rehabilitation: early supported discharge with rehabilitation in a day unit or at home, and traditional uncoordinated treatment (control).

\section{METHODS}

\section{Design overview}

The study was conducted in the context of a larger single-blinded randomised controlled trial (RCT), the Early Supported Discharge after Stroke in Bergen (ESD Stroke Bergen), registered in ClinicalTrials.gov (NCT00771771). The ESD Stroke Bergen had a predetermined inclusion period of 3 years, and the protocol is published. ${ }^{10}$

\section{Participants and allocation}

The study was conducted at a university hospital in collaboration with the primary healthcare services. The patients were recruited from the hospital stroke unit during the period 8 December 2008 to 20 December 2011. Follow-up assessment was performed 3 months after inclusion and was completed on 29 March 2012. A stroke unit physician assessed eligibility for inclusion. Inclusion criteria: patients had to live in Bergen and at home prior to the stroke, be included within 7 days after stroke onset and between 6 and $120 \mathrm{~h}$ after admission to the stroke unit, be awake and have a National Institutes of Health Stroke Scale (NIHSS) $)^{11-13}$ score of 2-26. Exclusion criteria were serious psychiatric disorder, current alcohol or substance abuse, serious comorbidity such as terminal cancer or insufficient Norwegian language skills. The patients were given a folder containing written information about the study, and their written informed consent was necessary. If this was not possible, consent was given by the next of kin, with written patient confirmation as soon as this became possible. This procedure was approved by the regional ethics committee. For this study, only patients who were discharged directly to their homes from the stroke unit and assessed by the primary outcome measure Postural Assessment Scale for Stroke (PASS) ${ }^{14}$ were included.

Baseline testing was performed after inclusion and before randomisation for the main study. For allocation of the patients, we used a computer-generated list of random numbers in blocks of six (two patients allocated to each group) generated by an independent researcher at the local university. The person recruiting participants did not have access to the randomisation list. A nurse at the stroke unit was responsible for giving the allocated patients written information about their assigned groups.

Four experienced neurorehabilitation physiotherapists conducted the physical capacity tests of gait and balance and collected related self-reports. To assure standardisation, the physiotherapists underwent a period of training prior to the study in order to learn to use the physical tests. Neurologists were responsible for assessing NIHSS, and trained stroke nurses assessed the Barthel index $(\mathrm{BI})^{15} 16$ and modified Rankin Scale $(\mathrm{mRS})^{17}$ at baseline. At 3 months, BI and mRS were administered by a trained physiotherapist. All outcome assessors were blinded to the group of the patient. The patients were retested at the hospital outpatient clinic 3 months after inclusion.

\section{Interventions}

For the experimental groups, two designated coordinated multidisciplinary teams, one hospital outreach team and one community healthcare team were established to facilitate early discharge. Each team consisted of a nurse, a physiotherapist and an occupational therapist. The hospital outreach team organised the transition from the hospital to the patient's home. The community healthcare team was responsible for rehabilitation and actual treatment for up to 5 weeks after discharge from the stroke unit. The nurse was the team leader and coordinator. The teams communicated and cooperated closely. Patients were discharged from the hospital to their own homes as early as possible.

Experimental group I, day unit rehabilitation: patients travelled from home to a local day rehabilitation unit to receive treatment from the community healthcare team. Treatment was mainly physiotherapy and occupational therapy and focused on impairment in body function as well as task-oriented training.

Experimental group II, home rehabilitation: patients received treatment from the community healthcare team in their own homes. Treatment was mainly physiotherapy and occupational therapy and focused on task-oriented training in daily activities.

The planned main difference between the experimental groups was the context in which patients received their rehabilitation interventions.

Control group, traditional treatment: patients followed a routine discharge procedure with outpatient therapy on an ad hoc basis. Treatment by various healthcare professionals depended on the patients' needs and 
consisted mostly of physiotherapy, either at home or in private physiotherapy practices. Other health professions could be involved (occupational therapy and home nursing); however, the interventions were uncoordinated and mainly unidisciplinary.

Patients in all groups received speech therapy on an outpatient basis if needed.

\section{Outcomes and follow-up}

All patients were evaluated with a wide range of medical, ADL, physical capacity and self-report measures at baseline and 3 months after inclusion. Brain scans using CT or MRI were performed shortly after admission to the stroke unit.

\section{Primary outcome measure}

PASS was used to assess ability to maintain a position and to maintain equilibrium during positional changes such as turning in bed, sitting up from a supine position, standing up, picking an object off the floor and standing on one leg. ${ }^{14}{ }^{18}$ Combined, these comprise a measure within the activity domain of the International Classification of Functioning, Disability and Health (ICF). ${ }^{19}$ PASS contains 12 items $(0-36$, highest score best) and has shown high sensitivity to change in postural control during the first 3-6 months post stroke. ${ }^{14} 2021$ Smallest detectable change (SDC) is $\geq 4$ points. ${ }^{22}$ PASS has demonstrated high internal consistency, good psychometric properties and predictive ability for ADL function 1 year after stroke. ${ }^{20}$

\section{Secondary outcome measures}

The Trunk Impairment Scale-modified Norwegian version (TIS-modNV) was used to evaluate impairment of trunk control post stroke, ${ }^{23}$ the ICF domain being body function. ${ }^{24} 25$ The scale consists of six ordinal items that assess postural control of the trunk in a sitting position. It has demonstrated good construct validity, excellent internal consistency and high inter-tester and test-retest reliability for the total score (0-16, highest score best). SDC is $\geq 3$ points. ${ }^{23}$

Functional ambulation categories categorise the patient's walking ability in six levels $(0-5$, highest category best). ${ }^{26}$ The ICF domain is activity. Stairs, and a $10 \mathrm{~m}$ indoor walking distance, is needed in order to discern between categories 4 and 5 . The test has demonstrated good reliability, validity and sensitivity to change during the first 6 months post stroke.

Timed Up-and-Go (TUG) ${ }^{27} 28$ is a test of balance, walking speed and ADL. The patient rises from a chair, walks $3 \mathrm{~m}$, turns, walks back to the chair and sits down. Time used for the entire sequence is measured. The ICF domain is activity. ${ }^{16}$ TUG is sensitive to change over time, has shown predictive ability for walking outdoors unaided $^{28}$ and has demonstrated acceptable reliability and validity in stroke. ${ }^{29}$ Time used was transformed to $\mathrm{m} / \mathrm{s}$ before analysis.
The $5 \mathrm{~m}$ timed walk $(5 \mathrm{mTW})^{3031}$ is a test for walking speed, the ICF domain being activity. 5mTW at a comfortable speed is seen to be the most responsive walking test during the first 5 weeks post stroke, and has been reported to correlate with functional ability and balance confidence. ${ }^{31}$ A recommended $1-2 \mathrm{~m}$ acceleration and deceleration phase was used, and time transformed to $\mathrm{m} / \mathrm{s}$. This test was not included until the end of February 2009, and the first 13 patients were not tested.

Patients who were unable to walk were given a score of $0 \mathrm{~m} / \mathrm{s}$ in the walking tests.

\section{Self-report measures}

Numerical Rating Scales ${ }^{32}$ are 11-point scales $(0-10$, lowest score best), and were used to uncover the patient's own perception of stroke-related problems with walking, balance, ADL, safety in physical activity (ICF domain: activity), pain and tiredness (ICF domain: body function).

\section{Other background information measures}

NIHSS is used to assess initial impairment, including motor and sensory function, speech and language. ${ }^{11} 12$ The scale used in this study was a 13-item Norwegian version $(0-34$, lowest score best $)$, where mild stroke $=0-7$, moderate $=8-14$ and severe $\geq 15$. $^{13}$

$\mathrm{BI}$ is a 10 -item scale $(0-100$, highest score best) used to assess the patient's dependence on ADL function. ${ }^{15} 16$ Dependence on ADL is defined as $<95 .{ }^{33} 34$

$\mathrm{mRS}$ is a 7-level scale (0-6, lowest score best) used to measure outcome related to dependency, defined as equivalent to $\mathrm{mRS}>2 .{ }^{17}$

\section{Sample size calculation}

To detect a mean difference in change in PASS of 4 points (SDC) from baseline to 3 months between the three groups assuming an SD of 3.2 points ${ }^{35}$ for the change scores at significance level $5 \%(\alpha=0.05)$, at least 20 patients in each group would give a power of at least $90 \%$ (analysis of variance F-test; this assumes that the mean changes are equally spaced between the three groups; with a more extreme distribution, the power increases). The statistical program SamplePower V.2 was used to determine the power of the study. The ESD Stroke Bergen Study used a different main outcome measure than did this study, and the predetermined inclusion period of 3 years was therefore expected to yield a greater amount of data than was needed for our study alone.

\section{Statistics}

Descriptive statistics were used for the background variables and baseline and change scores of the physical capacity tests and self-report measures. To compare baseline data of patients who were tested with PASS at baseline and at 3 months with those who were not tested with PASS at 3 months, either the independent $t$ test or Mann-Whitney U test was used for continuous variables 
depending on the distribution, and the $\chi^{2}$ test was used for categorical variables.

One-way analysis of variance was used to compare baseline scores between the three groups. When data were not distributed normally or were categorical, the corresponding non-parametric statistical tests were used (Kruskal-Wallis, $\chi^{2}$, respectively).

The non-parametric statistical test (Kruskal-Wallis) was used to compare the difference in change between the groups as the change scores were not normally distributed. If a statistically significant difference $(p<0.05)$ between groups was found in the analysis, pairwise tests for independent groups were performed (Mann-Whitney U test) using significance level $\mathrm{p}=0.05$ / $3=0.0167$ to adjust for multiple comparisons. Simple (unadjusted), multiple (fully adjusted) and backward stepwise multiple linear regression analyses were performed for PASS scores at 3 months as the dependent variable on group allocation including age, gender, cohabitation, diagnosis, diabetes, previous stroke, previous nursing care, thrombolysis, baseline NIHSS scores and baseline scores of PASS. The statistical programs package SPSS V.21 (SPSS Inc, Chicago, Illinois, USA) was used for all data analyses.

\section{RESULTS}

During the inclusion period, 1749 patients were admitted to the stroke unit, of which 1443 did not meet the inclusion criteria. The main reasons for exclusion were living outside of Bergen or not having suffered a confirmed stroke. This left 319 patients who were eligible to take part in the main trial, ESD Stroke Bergen. Of these, 13 declined to participate; 306 patients were willing to participate. These were randomised into three groups (figure 1). For this study, 21 patients who were not tested with PASS at baseline and 118 patients who were not discharged directly home after their stay in the stroke unit were excluded. This resulted in 167 eligible patients: 52 in the day unit group, 60 in the home rehabilitation group and 55 in the control group. In the day unit group, $25(48 \%)$ were lost to follow-up, in the home-rehabilitation group $17(28 \%)$ and in the control group $20(36 \%)$, a total of $62(37 \%)$. Three patients in total, one in the day unit group and two in the home rehabilitation group, did not receive the allocated intervention, but were tested at both points in time and were included in intention-to-treat analyses.

Baseline characteristics are shown in table 1 . The patients who were not retested were older, fewer lived with a partner, and they had a higher incidence of previous stroke and previous nursing care.

The patients who were retested after 3 months demonstrated higher (better) baseline scores on PASS, BI, TUG and 5mTW than did the patients who were not retested (table 2). Both patient groups had rather high PASS scores at baseline, ranging between 17 and 36 (median 32 and 30 of retested and not-retested patients, respectively), that is, they had mostly mild-to-moderate disability.

Comparisons between the groups at baseline demonstrated no difference for any physical outcome measure (table 3). The median score for PASS was high, and the mean (SD) walking speed ( $5 \mathrm{mTW})$ was above community walking speed, estimated as $\geq 0.8 \mathrm{~m} / \mathrm{s}^{36} 37$ for all groups. The mean (SD) length of stay in the stroke unit was 8.6 (4.8) days with no significant difference between the groups, $\mathrm{p}=0.948$; day unit, mean $(\mathrm{SD})$, minimummaximum: 8.6 (3.3), 3-17; home rehabilitation: 8.7 (3.9), 3-18; control: 8.4 (4.5), 3-22.

Because of the substantial number of patients excluded or lost to follow-up after randomisation to the RCT study, we compared baseline characteristics and test scores of patients who were included in the study. There were no differences between the day unit, home rehabilitation and control groups for any background characteristics (web-only file).

The mean (SD) time between test and retest was 13.4 (1.7) weeks, with no difference between the groups. There was no statistically significant difference in loss to follow-up between the groups, $\mathrm{p}=0.097$, and no difference in change between the groups for the main outcome PASS (table 4). A significant difference in change between the groups was shown for TIS-modNV and for self-reports on walking and ADL. Patients in the home rehabilitation group showed greater trunk control improvement than did those in the day unit and control groups. However, pairwise analyses adjusted for multiple comparisons were non-significant: day unit versus home rehabilitation, $\mathrm{p}=0.031$; day unit versus control, $\mathrm{p}=0.886$; home rehabilitation versus control, $\mathrm{p}=0.040$. Self-report on problems with walking demonstrated greatest improvement in the day unit group, with pairwise analyses showing a significantly greater improvement for those in the day unit group as compared with the control group: day unit versus home rehabilitation, $\mathrm{p}=0.215$; day unit versus control, $\mathrm{p}=0.004$; home rehabilitation versus control, $\mathrm{p}=0.126$. Self-report on ADL demonstrated that patients in the day unit and home rehabilitation groups improved more than did those in the control group, with a significant difference between the home rehabilitation and control groups: day unit versus home rehabilitation, $\mathrm{p}=0.774$; day unit versus control, $\mathrm{p}=0.036$; home rehabilitation versus control, $\mathrm{p}=0.006$. No other pairwise comparisons demonstrated significant differences in change. The patients in the day unit group showed improvement above a clinically important change in walking $(0.175 \mathrm{~m} / \mathrm{s})$.

Multiple regression analyses for PASS at 3 months demonstrated a significant negative effect of increased age $(b=-0.070)$, positive effect of higher baseline PASS scores $(b=0.394)$, positive effect of not having previous cerebral lesion $(b=2.621)$ and positive effect of not having had previous nursing care $(b=1.220)$ with an explained variance of $63 \%$ in the final model after backward stepwise selection. The control group had higher 
Figure 1 Flow chart of patients allocated to the Balance and Walking study, from randomised groups of the Early Supported Discharge (ESD) Stroke Bergen study. PASS, Postural Assessment Scale for Stroke.

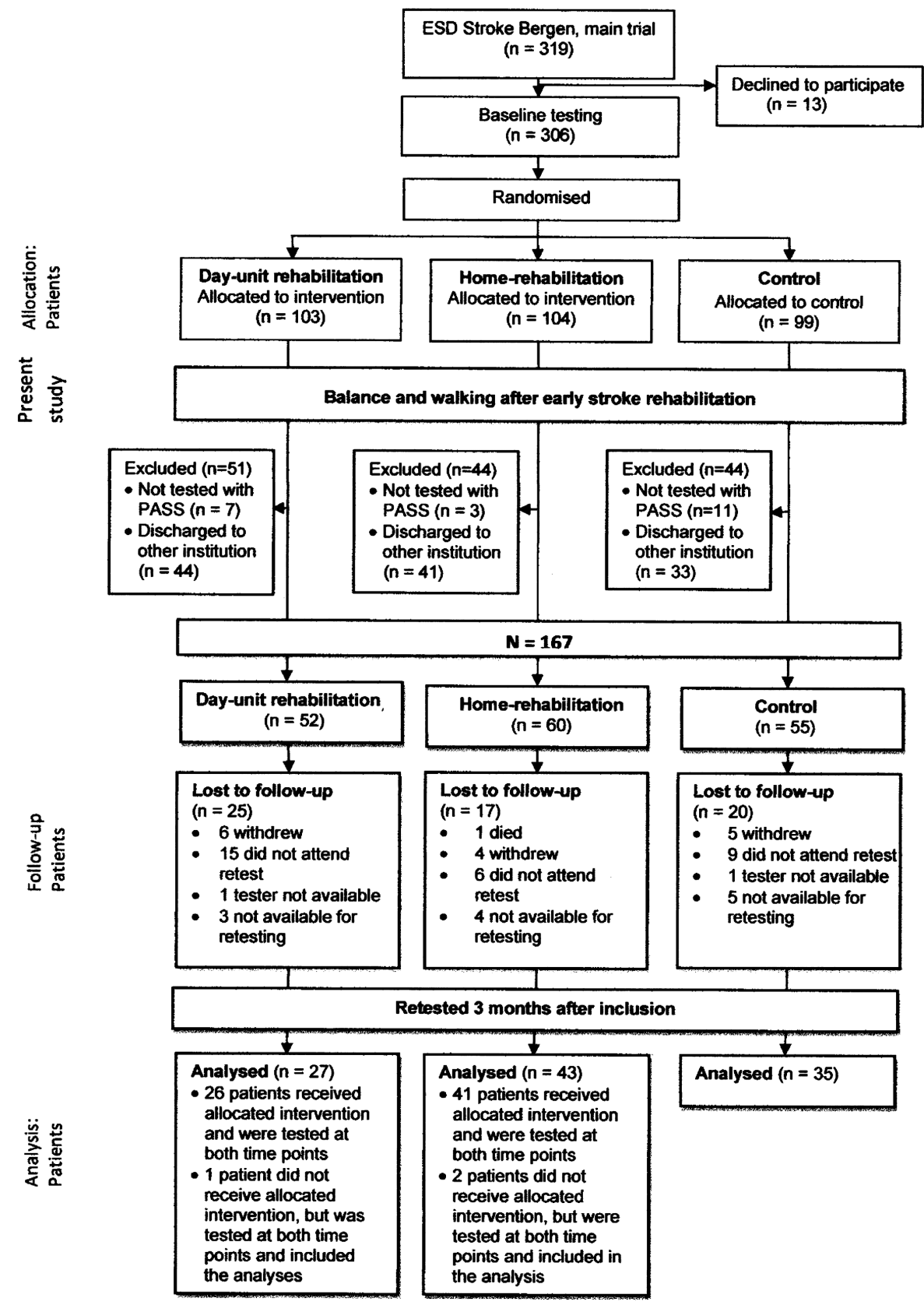

means than did the other groups, that is, the unadjusted differences in means (95\% CI) between the control and day unit groups were $-0.194(-1.823$ to 1.436$)$, and between the control and home rehabilitation groups -0.599 (-2.048 to 0.840$)$. Group allocation was not a significant predictor for PASS, either unadjusted $(\mathrm{p}=0.720)$ or adjusted for the other variables.

The total intensity of treatment from the community healthcare team amounted to mean (SD), minimummaximum: 22.0 (9.5), 4.0-50.1 h for the day unit group and $16.6(9.0), 0.5-48.5 \mathrm{~h}$ for the home rehabilitation group. The mean difference $(95 \% \mathrm{CI})$ between the groups was $5.4 \mathrm{~h}(1.61,9.12), \mathrm{p}=0.006$. The duration lasted 4.4 weeks for the day unit patients and 4.2 weeks for the home rehabilitation patients, $p=0.240$. The intervention was mainly given by a physiotherapist or occupational therapist. In addition, patients were advised to do exercises at home 2 days/week, mainly related to activities and participation, individually adjusted to the patients' needs in time and content. ${ }^{38}$

\section{DISCUSSION}

We did not find any significant differences in change between the day unit, home rehabilitation or control groups for the primary outcome measure PASS, or for the length of stroke unit stay. The patients in this study were shown to have mainly mild-to-moderate disability after stroke. Significant differences in change between the three groups were shown for the secondary outcome measures of trunk control and self-report on walking and ADL. Pairwise comparisons demonstrated a larger 
Table 1 Baseline characteristics of all patients $(\mathrm{N}=167)$ discharged home after stroke unit stay

\begin{tabular}{|c|c|c|c|c|c|c|c|c|c|c|c|}
\hline \multirow{3}{*}{$\begin{array}{l}\text { Variables } \\
\text { Age; mean (SD), min, } \max \\
\text { Gender; } n(\%)\end{array}$} & \multicolumn{3}{|l|}{$\begin{array}{l}\text { All } \\
N=167\end{array}$} & \multicolumn{3}{|c|}{$\begin{array}{l}\text { Tested and retested } \\
\text { with PASS } \\
\mathrm{n}=105\end{array}$} & \multicolumn{3}{|c|}{$\begin{array}{l}\text { Not retested } \\
\text { with PASS } \\
\mathrm{n}=62\end{array}$} & \multirow{3}{*}{$\begin{array}{c}\text { p Value } \\
0.001 \\
0.333\end{array}$} & \multirow{3}{*}{$\begin{array}{l}\text { Statistic } \\
\mathrm{t} \text { test } \\
\chi^{2} \text { test }\end{array}$} \\
\hline & 70.4 & $(13.2)$ & 29,98 & 69.1 & $(12.7)$ & 29,94 & 76.0 & $(12.2)$ & 42,98 & & \\
\hline & & & & & & & & & & & \\
\hline Male & 95 & (57) & & 63 & $(60)$ & & 32 & (52) & & & \\
\hline Female & 72 & (43) & & 42 & (40) & & 30 & $(48)$ & & & \\
\hline Living with partner; n (\%) & 103 & (62) & & 77 & (73) & & 26 & (42) & & $<0.001$ & $\chi^{2}$ test \\
\hline Stroke diagnosis; n (\%) & & & & & & & & & & 0.090 & $\chi^{2}$ test \\
\hline Ischaemic & 152 & (91) & & 99 & (94) & & 53 & $(86)$ & & & \\
\hline Haemorrhagic & 15 & (9) & & 6 & (6) & & 9 & (15) & & & \\
\hline Localisation of lesion; n (\%) & & & & & & & & & & 0.457 & $\chi^{2}$ test \\
\hline Right hemisphere & 60 & (36) & & 36 & (34) & & 24 & (38) & & & \\
\hline Left hemisphere & 71 & (43) & & 46 & (44) & & 25 & (40) & & & \\
\hline Bilateral & 7 & $(4)$ & & 5 & (5) & & 2 & (3) & & & \\
\hline Brainstem & 19 & (11) & & 14 & (13) & & 5 & (8) & & & \\
\hline Cerebellum & 10 & (6) & & 4 & (4) & & 6 & (10) & & & \\
\hline Most affected body half; n (\%) & & & & & & & & & & 0.942 & $\chi^{2}$ test \\
\hline Right & 94 & (56) & & 60 & (57) & & 34 & $(55)$ & & & \\
\hline Left & 70 & (42) & & 43 & (41) & & 27 & (43) & & & \\
\hline Bilateral & 3 & $(7)$ & & 2 & $(2)$ & & 1 & (2) & & & \\
\hline Thrombolysis; n (\%) & 20 & (12) & & 13 & (12) & & 7 & $(11)$ & & 1.000 & $\chi^{2}$ test \\
\hline Diabetes; n (\%) & 27 & (16) & & 19 & (18) & & 8 & (13) & & 0.514 & $\chi^{2}$ test \\
\hline Previous stroke; n (\%)† & 38 & (23) & & 18 & (17) & & 20 & (32) & & 0.036 & $\chi^{2}$ test \\
\hline Previous nursing care; n (\%) & 12 & $(7)$ & & 4 & $(4)$ & & 8 & (8) & & 0.034 & $\chi^{2}$ test \\
\hline $\begin{array}{l}\text { Days stroke unit; mean (SD), } \\
\text { min, max }\end{array}$ & 8.6 & (5) & 2,43 & 8.7 & (4) & 3,22 & 8.4 & (6) & 2,43 & 0.732 & t test \\
\hline
\end{tabular}

improvement in self-reported walking in the day unit group as compared with the control group, and a greater improvement in self-reported ADL after home rehabilitation as compared with the control group. As expected, age and baseline scores of PASS explained most of the change in PASS at 3 months.

This study's strengths lie in the use of objective and self-report outcome measures by blinded assessors for the comparison of balance and walking between study groups, and in the body function and activity domains of the ICF being captured by the tests. This study was designed with early supported discharge for the day unit and home rehabilitation groups in mind; unexpectedly, however, patients in the control group were discharged from the stroke unit just as early. The acute management of stroke in stroke units has changed over the last decade and is constantly developing, especially for patients with ischaemic strokes. ${ }^{13}$ In addition, health authorities in the primary healthcare system in Norway are required to offer appropriate care and rehabilitation for patients discharged after hospital treatment. As a consequence, patients tend to be discharged earlier than was previously the case. Patients with mild-tomoderate disability seem to be most suitable for early supported discharge. ${ }^{3} 439$ The patients who were discharged directly home were shown to have an overall mild-to-moderate level of function at baseline, scoring a median of 32 points on PASS. A BI above 80/100 is defined as mild disability. ${ }^{40}$ Only a few patients were in the severe category as shown in table 3 . Our results are therefore representative for rehabilitation models that aim for early supported discharge. However, the results of this study cannot be extended to patients with stroke with poorer baseline physical function.

We did not find any differences in change between the groups in regard to PASS. Spontaneous recovery, ${ }^{41} 42$ combined with generally high baseline scores that imply a ceiling effect, might explain this result. However, no differences were found in previous studies between experimental and control groups on early supported discharge where physical capacity tests were used as the main outcome. ${ }^{6-8}$ The outcome measures used in those studies differed from those used in this study. For example, walking was tested differently in WidenHolmquist et al, ${ }^{8}$ Askim et at and in our study, and therefore no direct comparison between the studies is possible.

We found a difference between the groups for trunk control which improved above SDC in the home rehabilitation patients. A relationship between trunk control and functional ability in daily life in patients after stroke has also been indicated in other studies. ${ }^{35} 43-46$ Self-reported 
Table 2 Comparison of physical function at baseline between patients tested with PASS at both time points and patients who were not retested with PASS at 3 months, $\mathrm{N}=167$

\begin{tabular}{|c|c|c|c|c|c|c|c|c|c|c|}
\hline \multirow[b]{2}{*}{ Variables } & \multicolumn{4}{|c|}{$\begin{array}{l}\text { Tested and retested with PASS } \\
n=105\end{array}$} & \multirow[b]{2}{*}{$\mathbf{n}$} & \multicolumn{3}{|c|}{$\begin{array}{l}\text { Not retested with PASS } \\
n=62\end{array}$} & \multirow[b]{2}{*}{ p Value } & \multirow[b]{2}{*}{ Statistic } \\
\hline & $\mathbf{n}$ & Median & (IQR) & Min, $\max$ & & Median & (IQR) & Min, max & & \\
\hline PASS & 105 & 32 & (5) & 17,36 & 62 & 30 & (5) & 18,36 & $<0.001$ & $M-W$ \\
\hline FAC; n (\%) & 105 & 5 & (1) & 1,5 & 62 & 4 & (2) & 0,5 & 0.293 & $\chi^{2}$ test \\
\hline
\end{tabular}

$\begin{array}{lr}0 & 0 \\ 1 & 2 \\ 2 & 5 \\ 3 & 17 \\ 4 & 26 \\ 5 & 55 \\ \text { NIHSS } & 105 \\ \text { BI }^{*} & 104 \\ \text { mRS } & 105\end{array}$

$(-)$

(2)

(5)

(16)

(25)

(52)

$\begin{array}{rlll}3 & (2) & 0,13 & 25 \\ 100 & (0) & 65,100 & 62 \\ 2 & (1) & 0,4 & 62\end{array}$

(2)

(3)

(7)

(27)

(21)

(40)

$\begin{array}{rrlll}3 & (3) & 0,26 & 0.378 & M-W \\ 100 & (10) & 5,100 & 0.043 & M-W \\ 2 & (1) & 0,4 & 0.233 & \chi^{2} \text { test }\end{array}$

\begin{tabular}{|c|c|c|c|c|c|c|c|c|c|c|c|c|}
\hline 0 & 8 & (8) & & & & 3 & (5) & & & & & \\
\hline 1 & 23 & (22) & & & & 12 & (19) & & & & & \\
\hline 2 & 59 & (56) & & & & 29 & (47) & & & & & \\
\hline 3 & 11 & (11) & & & & 14 & (23) & & & & & \\
\hline 4 & 4 & (4) & & & & 4 & (7) & & & & & \\
\hline & $\mathbf{n}$ & & Mean & (SD) & Min, max & $\mathbf{n}$ & & Mean & (SD) & Min, max & & \\
\hline TIS-modNV & 105 & & 10.73 & (3.64) & 3,16 & 62 & & 9.43 & (3.90) & 1,16 & 0.799 & t test \\
\hline TUG m/s & 105 & & 0.59 & $(0.27)$ & $0.00,1.27$ & 62 & & 0.41 & $(0.26)$ & $0.00,1.00$ & $<0.001$ & t test \\
\hline $5 \mathrm{mTW} \mathrm{m} / \mathrm{s} \dagger$ & 94 & & 0.99 & $(0.37)$ & $0.00,1.84$ & 59 & & 0.78 & $(0.40)$ & $0.00,1.62$ & 0.002 & $\mathrm{t}$ test \\
\hline
\end{tabular}

Significant values marked in italic.

${ }^{*}$ Missing information on one patient.

t13 Patients were not tested at baseline.

5mTW, 5 m timed walk; BI, Barthel Index; FAC, functional ambulation categories; M-W, Mann-Whitney U test; mRS, modified Rankin Scale; NIHSS, National Institutes of Health Stroke Scale;

PASS, Postural Assessment Scale for Stroke; TIS-modNV, Trunk Impairment Scale modified Norwegian version; TUG, timed Up-and-Go. 
Table 3 Baseline scores of the physical and self-report measures, and comparison between experimental and control groups ( $N=167)$

\begin{tabular}{|c|c|c|c|c|c|c|c|c|c|c|c|c|c|c|c|}
\hline \multirow{2}{*}{\multicolumn{2}{|c|}{ Variables }} & & \multicolumn{3}{|c|}{$\begin{array}{l}\text { Day unit } \\
n=52\end{array}$} & \multicolumn{4}{|c|}{$\begin{array}{l}\text { Home rehabilitation } \\
\mathrm{n}=60\end{array}$} & \multirow[t]{2}{*}{$\begin{array}{l}\text { Control } \\
\mathrm{n}=55\end{array}$} & \multirow[b]{2}{*}{ Median } & \multirow[b]{2}{*}{ (IQR) } & \multirow[b]{2}{*}{ Min, $\max$} & \multirow[b]{2}{*}{ p Value } & \multirow[b]{2}{*}{ Statistic } \\
\hline & & & Median & (IQR) & Min, $\max$ & & Median & (IQR) & Min, $\max$ & & & & & & \\
\hline PAS & & & 31 & (6) & 18,36 & & 31 & (5) & 17,36 & & 31 & (3) & 20,36 & 0.964 & K-W \\
\hline FAC & & & 5 & (2) & 0,5 & & 4 & (2) & 1,5 & & 5 & (2) & 1,5 & 0.365 & $\chi^{2}$ test \\
\hline \multicolumn{3}{|c|}{ FAC; n (\%) } & & & & & & & & & & & & & \\
\hline 0 & 1 & (19) & & & & $0(-)$ & & & & $0(-)$ & & & & & \\
\hline 1 & 0 & $(-)$ & & & & 2 (3) & & & & $2(4)$ & & & & & \\
\hline 2 & 4 & (8) & & & & $4(7)$ & & & & $1(2)$ & & & & & \\
\hline 3 & 12 & (23) & & & & $11(18)$ & & & & $11(20)$ & & & & & \\
\hline 4 & 8 & (15) & & & & $19(32)$ & & & & $12(22)$ & & & & & \\
\hline 5 & 27 & (52) & & & & $24(40)$ & & & & 29 (53) & & & & & \\
\hline NIHS & & & 3 & (3) & 1,25 & & 3 & (3) & 0,11 & & 2 & (3) & 0,26 & 0.275 & $\mathrm{~K}-\mathrm{W}$ \\
\hline $\mathrm{Bl}^{*}$ & & & 100 & (0) & 5,100 & & 100 & (9) & 50,100 & & 100 & (5) & 50,100 & 0.390 & K-W \\
\hline \multirow{2}{*}{\multicolumn{3}{|c|}{ mRS; n (\%) }} & & & & & & & & & & & & 0.971 & $\chi^{2}$ test \\
\hline & & & & & & & & & & & & & & & \\
\hline 0 & 4 & (8) & & & & $4(7)$ & & & & $3(6)$ & & & & & \\
\hline 1 & 13 & (25) & & & & $11(18)$ & & & & $11(20)$ & & & & & \\
\hline 2 & 27 & (52) & & & & $32(53)$ & & & & 29 (53) & & & & & \\
\hline 3 & 7 & (14) & & & & $9(15)$ & & & & $9(17)$ & & & & & \\
\hline \multirow[t]{2}{*}{4} & 1 & (2) & & & & $4(7)$ & & & & $3(6)$ & & & & & \\
\hline & & & Mean & (SD) & Min, max & & Mean & (SD) & Min, max & & Mean & (SD) & Min, max & & \\
\hline \multicolumn{3}{|c|}{ TIS-modNV } & 10.48 & (3.95) & 1,16 & & 9.52 & (3.51) & 1,16 & & 10.73 & (3.86) & 1,16 & 0.192 & ANOVA \\
\hline \multicolumn{3}{|c|}{ TUG m/s } & 0.52 & (0.30) & $0.00,1.15$ & & 0.52 & $(0.27)$ & $0.00,1.27$ & & 0.53 & $(0.28)$ & $0.00,1.13$ & 0.988 & ANOVA \\
\hline \multirow{2}{*}{\multicolumn{3}{|c|}{ NRSt }} & 0.88 & (0.41) & $0.00,1.46$ & & 0.91 & (0.39) & $0,00,1.56$ & & 0.93 & $(0.41)$ & $0.00,1.84$ & 0.830 & ANOVA \\
\hline & & & & & & & & & & & & & & & \\
\hline \multicolumn{3}{|c|}{ Walking } & 3.5 & (2.7) & 0,10 & & 3.6 & (2.8) & 0,10 & & 3.0 & (2.7) & 0,10 & 0.444 & ANOVA \\
\hline \multicolumn{2}{|c|}{ Balance } & & 3.4 & (2.8) & 0,10 & & 4.1 & (2.9) & 0,10 & & 3.3 & (2.6) & 0,10 & 0.245 & ANOVA \\
\hline \multicolumn{2}{|c|}{$\mathrm{ADL}$} & & 2.6 & (2.7) & 0,10 & & 3.3 & (2.9) & 0,10 & & 2.2 & (2.5) & 0,8 & 0.084 & ANOVA \\
\hline \multicolumn{2}{|c|}{$\begin{array}{l}\text { Physical } \\
\text { activity }\end{array}$} & & 2.7 & (3.0) & 0,10 & & 3.0 & (2.9) & 0,10 & & 2.3 & (2.2) & 0,8 & 0.420 & ANOVA \\
\hline \multicolumn{2}{|c|}{ Pain } & & 1.1 & (1.9) & 0,9 & & 1.3 & (2.4) & 0,10 & & 1.3 & (2.1) & 0,7 & 0.865 & ANOVA \\
\hline & dness & & 3.1 & (2.7) & 0,10 & & 3.5 & (2.5) & 0,10 & & 3.4 & (2.8) & 0,8 & 0.810 & ANOVA \\
\hline
\end{tabular}

*Missing $\mathrm{Bl}$ : one control.

†Missing NRS 1, NRS 2, NRS 3, NRS 4, NRS 6: two in day unit group, two in home rehabilitation group, two in control group; missing NRS 5: one in day unit group, two in home rehabilitation group, two in control group.

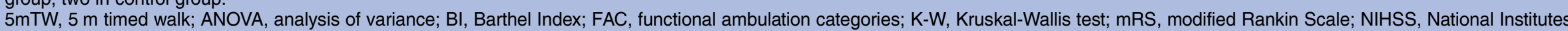

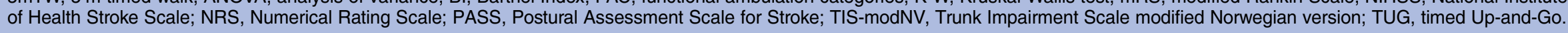




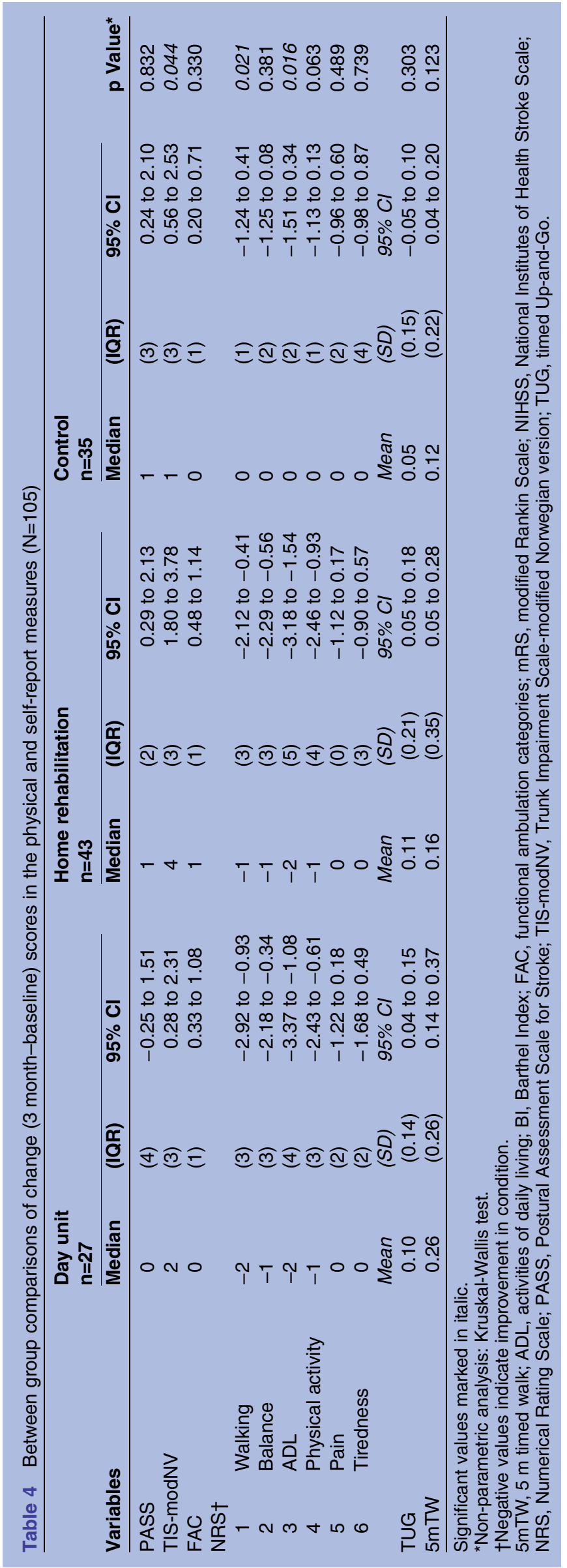

ADL improved more in the day unit and home rehabilitation groups, with pairwise comparisons demonstrating a significantly greater change only for the home rehabilitation group as compared with the control group. Differences between groups in ADL function have not been reported in previous studies on ESD as compared with ordinary service, ${ }^{13}$ but patients' perception of problems with ADL has not been reported previously. We would have expected that patients who receive treatment to improve daily tasks in the functional context of their own homes would improve these skills more than patients in the day unit and control groups. It is recommended that such treatment be meaningful and repetitive, ${ }^{47} 48$ and repetitive task-oriented training has been found to result in small amounts of improvement in $\mathrm{ADL},{ }^{49}$ which may explain why the home rehabilitation group experienced most improvement. The groups demonstrated a mean moderate trunk control at baseline, and for patients with this level of trunk control, home rehabilitation would therefore seem to be most effective.

The patients' perception of problems with walking improved most in the day unit group, with a significant difference demonstrated between the day unit and control groups. Also, walking speed improved above clinically important change, estimated as $\geq 0.175 \mathrm{~m} / \mathrm{s}^{30}$ in the day unit group, but not in the home rehabilitation and control groups (table 4). Interestingly, a recent study found a significant relationship between selfreported walking ability and gait performance in chronic patients with stroke ${ }^{50}$ which supports our finding. Travelling to a day unit several times per week might have given the patients enhanced gait training effects $^{9}$ as well as experience with a larger area in which to move and varied environments. In addition, the day unit patients received on average more treatment from the community healthcare team than the home rehabilitation group. More therapy time and more intensity of therapy seem to be beneficial for functional outcome $^{5152}$ and could explain why walking seemed to improve more in this group. For walking speed, day unit rehabilitation would therefore seem most effective.

Whether a mean of 22.0 and $16.6 \mathrm{~h}$ of treatment over a 4-week period is considered intensive in a subacute phase after stroke remains to be explored. Our patients had mostly mild-to-moderate disability and received an intensity and duration of treatment adjusted to their individual needs. There was a similar maximum intensity given to those patients with the greatest need in the day unit and home rehabilitation groups.

The patients in the original trial (ESD Stroke Bergen) were randomised to three groups, making them comparable in regard to background variables and test scores. As a large portion of the patients were excluded or lost to follow-up, we could not be sure that the patients who remained in the groups in this study were still comparable. However, analysis of our study patients demonstrated no statistically significant difference between the groups, either in demographic or in test variables at 
baseline. However, there was a non-significant difference in loss to follow-up between the groups. The loss to follow-up is a weakness in the study. Patients who were lost to follow-up were older, more of them lived alone and they had a poorer baseline function; therefore, attending retesting might have been too challenging. Real differences might therefore have gone undetected. A recommendation for future studies would be to undertake retesting in the patients' homes if possible, to minimise loss to follow-up. Another weakness in this study is the fact that we did not register the extent to which the patients in the control group had received treatment. When comparing outcomes of the groups, this knowledge would have been advantageous.

More research is needed to investigate which rehabilitation context is most effective for various aspects of physical function, as well as in patients with poorer baseline function.

\section{CONCLUSION}

There was no difference in change of postural balance assessed by PASS at 3 months after stroke. For the secondary outcomes, home rehabilitation and day unit treatment tended to be more effective for trunk control, perception of walking and ADL than traditional treatment. Day unit patients improved above clinically important change in walking speed.

\section{Author affiliations \\ ${ }^{1}$ Department of Physiotherapy, Haukeland University Hospital, Bergen, Norway ${ }^{2}$ Department of Global Public Health and Primary Care, Physiotherapy Research Group, University of Bergen, Norway ${ }^{3}$ Department of Physical Medicine and Rehabilitation, Haukeland University Hospital, Bergen, Norway \\ ${ }^{4}$ Centre for Clinical Research, Haukeland University Hospital, Bergen, Norway ${ }^{5}$ Department of Neurology, Haukeland University Hospital, Bergen, Norway ${ }^{6}$ Centre for Age-related Medicine, Stavanger University Hospital, Stavanger, Norway}

Acknowledgements The authors wish to thank all patients who willingly gave their informed consent to take part, and the physiotherapists who made significant contributions towards making the study possible: Torunn Grenstad and Veronica Bøe who tested the patients at all three points in time, Odd-Arne Bergset and Elisabeth Skjefrås Kvile who tested the patients at baseline and Silje Mæhle who organised the logistics at the 3-month and 6-month follow-up. We also wish to thank Amesto Translations who assisted with the editing of the paper.

Contributors BEBG was the main author of the study and was involved from the start of the ESD Stroke Bergen Study in relation to the physiotherapist's role in exploring physical function. Data from the physical capacity tests were used in this study. BEBG also trained the testers, assembled the database, did the background literature searches, performed the statistical analysis and wrote the article. $\mathrm{HH}$ was the research leader. He collected data for the ESD Stroke Bergen Study and has been involved in discussions and the writing process of this study. TS and LIS have been involved in all aspects of the study: planning, discussion of analyses and results and frequent feedback during the writing process. GEE is a biostatistician, and has been involved in power calculations, has given advice on and help with statistical analysis and discussion of the results as well as the writing process. HN has been involved in the planning of the study and recruitment of patients. He supplied some of the background information on the patients, and has been involved in discussions and the writing process. JSS was the project leader for the ESD
Stroke Bergen Study, and has been involved in discussions and the writing process for this study. BF was involved from the start with the planning of the physiotherapists' role in the ESD Stroke Bergen Study. She has been involved in discussions and the writing process of this study. SD collected and plotted the data from the balance and walking measures, and has been involved in discussions and the writing process.

Funding This work was supported by the Research Council of Norway, grant number 186528, the Norwegian Fund for Post-graduate Training (no grant number), Bergen Health Authority and the Regional Health Authority of Western Norway (no grant number).

Competing interests None.

Ethics approval Regional Committee for Medical and Health Research Ethics and the Norwegian Social Science Data Services.

Provenance and peer review Not commissioned; externally peer reviewed.

Data sharing statement The data are not yet anonymised and are still protected by the hospital. In addition, there are several future research articles planned from our research group. We are therefore unable to share the data at this point.

Open Access This is an Open Access article distributed in accordance with the Creative Commons Attribution Non Commercial (CC BY-NC 3.0) license, which permits others to distribute, remix, adapt, build upon this work noncommercially, and license their derivative works on different terms, provided the original work is properly cited and the use is non-commercial. See: http:// creativecommons.org/licenses/by-nc/3.0/

\section{REFERENCES}

1. Early Supported Discharge Trialists. Services for reducing duration of hospital care for acute stroke patients. Cochrane Database Syst Rev 2005;(2):CD000443.

2. Langhorne $P$, Taylor G, Murray G, et al. Early supported discharge services for stroke patients: a meta-analysis of individual patients' data. Lancet 2005;365:501-6.

3. Langhorne P, Holmqvist LW. Early supported discharge after stroke. J Rehabil Med 2007;39:103-8.

4. Fearon $P$, Langhorne P. Services for reducing duration of hospital care for acute stroke patients. Cochrane Database Syst Rev 2012;9: CD000443.

5. World Health Organization. The model of ICF. In: World Health Organization, ed. Towards a common language for functioning, disability and health. Geneva:WHO, 2002. http://www.who.int/ classifications/icf/training/icfbeginnersguide.pdf

6. Askim T, Morkved S, Indredavik B. Does an extended stroke unit service with early supported discharge have any effect on balance or walking speed? J Rehabil Med 2006;38:368-74.

7. Askim T, Morkved S, Engen A, et al. Effects of a community-based intensive motor training program combined with early supported discharge after treatment in a comprehensive stroke unit: a randomized, controlled trial. Stroke 2010;41:1697-703.

8. Widen-Holmquist $\mathrm{L}$, von Koch $\mathrm{L}$, Kostulas $\mathrm{V}$, et al. A randomized controlled trial of rehabilitation at home after stroke in southwest Stockholm. Stroke 1998;29:591-7.

9. Hillier S, Inglis-Jassiem G. Rehabilitation for community-dwelling people with stroke: home or centre based? A systematic review. Int $J$ Stroke 2010;5:178-86.

10. Hofstad H, Naess H, Moe-Nilssen R, et al. Early supported discharge after stroke in Bergen (ESD Stroke Bergen): a randomized controlled trial comparing rehabilitation in a day unit or in the patients' homes with conventional treatment. Int J Stroke 2013;8:582-7.

11. Goldstein LB, Samsa GP. Reliability of the National Institutes of Health Stroke Scale. Extension to non-neurologists in the context of a clinical trial. Stroke 1997;28:307-10

12. Meyer BC, Hemmen TM, Jackson CM, et al. Modified National Institutes of Health Stroke Scale for use in stroke clinical trials: prospective reliability and validity. Stroke 2002;33:1261-6.

13. Thomassen L, Waje-Andreassen U, Naess $\mathrm{H}$, et al. [Treatment of cerebrovascular disease in a comprehensive stroke unit]. Tidsskr Nor Laegeforen 2011;131:819-23.

14. Benaim C, Perennou DA, Villy J, et al. Validation of a standardized assessment of postural control in stroke patients: the Postural Assessment Scale for Stroke Patients. Stroke 1999;30:1862-8. 
15. Mahoney FI, Barthel LDW. Functional evaluation: the Barthel index. Md State Med J 1965;14:61-5.

16. Salter K, Jutai JW, Teasell R, et al. Issues for selection of outcome measures in stroke rehabilitation: ICF activity. Disabil Rehabil 2005;27:315-40.

17. Govan L, Langhorne P, Weir CJ. Categorizing stroke prognosis using different stroke scales. Stroke 2009;40:3396-9.

18. Clark E, Hill KD, Punt TD. Responsiveness of 2 scales to evaluate lateropulsion or pusher syndrome recovery after stroke. Arch Phys Med Rehabil 2012;93:149-55.

19. de Oliveira CB, de Medeiros I, Frota NA, et al. Balance control in hemiparetic stroke patients: main tools for evaluation. J Rehabil Res Dev 2008;45:1215-26.

20. Chien $\mathrm{CW}, \mathrm{Hu} \mathrm{MH}$, Tang PF, et al. A comparison of psychometric properties of the smart balance master system and the postural assessment scale for stroke in people who have had mild stroke. Arch Phys Med Rehabil 2007:88:374-80.

21. Mao HF, Hsueh IP, Tang PF, et al. Analysis and comparison of the psychometric properties of three balance measures for stroke patients. Stroke 2002;33:1022-7.

22. Liaw LJ, Hsieh CL, Lo SK, et al. The relative and absolute reliability of two balance performance measures in chronic stroke patients. Disabil Rehabil 2008;30:656-61.

23. Gjelsvik B, Breivik K, Verheyden G, et al. The Trunk Impairment Scale-modified to ordinal scales in the Norwegian version. Disabil Rehabil 2012;34:1385-95.

24. Tyson SF, Connell LA. How to measure balance in clinical practice. A systematic review of the psychometrics and clinical utility of measures of balance activity for neurological conditions. Clin Rehabil 2009;23:824-40.

25. Verheyden G, Nieuwboer A, Mertin J, et al. The Trunk Impairment Scale: a new tool to measure motor impairment of the trunk after stroke. Clin Rehabil 2004;18:326-34.

26. Mehrholz J, Wagner K, Rutte K, et al. Predictive validity and responsiveness of the functional ambulation category in hemiparetic patients after stroke. Arch Phys Med Rehabil 2007;88:1314-19.

27. Nilsagård Y, Hammer A. Timed up-and-go-ett test i tiden. Nordisk Fysioterapi 2003;7:32-48.

28. Podsiadlo D, Richardson S. The timed "Up \& Go": a test of basic functional mobility for frail elderly persons. $J$ Am Geriatr Soc 1991;39:142-8.

29. Ng SS, Hui-Chan CW. The timed up \& go test: its reliability and association with lower-limb impairments and locomoto capacities in people with chronic stroke. Arch Phys Med Rehabil 2005;86:1641-7.

30. Fulk GD, Ludwig M, Dunning K, et al. Estimating clinically important change in gait speed in people with stroke undergoing outpatient rehabilitation. J Neurol Phys Ther 2011;35:82-9.

31. Salbach NM, Mayo NE, Higgins J, et al. Responsiveness and predictability of gait speed and other disability measures in acute stroke. Arch Phys Med Rehabil 2001;82:1204-12.

32. Farrar JT, Young JP Jr, LaMoreaux L, et al. Clinical importance of changes in chronic pain intensity measured on an 11-point numerical pain rating scale. Pain 2001;94:149-58.
33. Indredavik B, Fjaertoft $\mathrm{H}$, Ekeberg $\mathrm{G}$, et al. Benefit of an extended stroke unit service with early supported discharge: a randomized, controlled trial. Stroke 2000;31:2989-94.

34. Mayo NE, Wood-Dauphinee S, Cote R, et al. There's no place like home-an evaluation of early supported discharge for stroke. Stroke 2000;31:1016-23.

35. Katz-Leurer M, Sender I, Keren O, et al. The influence of early cycling training on balance in stroke patients at the subacute stage. Results of a preliminary trial. Clin Rehabil 2006;20:398-405.

36. Carvalho C, Sunnerhagen KS, Willen C. Walking speed and distance in different environments of subjects in the later stage post-stroke. Physiother Theory Pract 2010;26:519-27.

37. Fritz S, Lusardi M. White paper: "walking speed: the sixth vital sign". $J$ Geriatr Phys Ther 2009;32:46-9.

38. Aasebø K, Rørlien K, Hauken JA, et al. [Report from a development project: day-unit and homebased rehabilitation. Part project of the ESD Stroke Bergen study]. Bergen, Norway: Municipality of Bergen, 2012.

39. Fisher RJ, Gaynor C, Kerr M, et al. A consensus on stroke: early supported discharge. Stroke 2011;42:1392-7.

40. Pan SL, Lien IN, Yen MF, et al. Dynamic aspect of functional recovery after stroke using a multistate model. Arch Phys Med Rehabil 2008:89:1054-60.

41. Kwakkel G, Kollen B, Twisk J. Impact of time on improvement of outcome after stroke. Stroke 2006;37:2348-53.

42. Nudo RJ. Neural bases of recovery after brain injury. J Commun Disord 2011;44:515-20.

43. Hsieh CL, Sheu CF, Hsueh IP, et al. Trunk control as an early predictor of comprehensive activities of daily living function in stroke patients. Stroke 2002;33:2626-30.

44. Kollen B, van de Port I, Lindeman E, et al. Predicting improvement in gait after stroke: a longitudinal prospective study. Stroke 2005;36:2676-80.

45. Likhi M, Jidesh VV, Kanagaraj R, et al. Does trunk, arm, or leg control correlate best with overall function in stroke subjects? Top Stroke Rehabil 2013;20:62-7.

46. Verheyden G, Vereeck L, Truijen S, et al. Trunk performance after stroke and the relationship with balance, gait and functional ability. Clin Rehabil 2006;20:451-8.

47. Langhorne $\mathrm{P}$, Coupar F, Pollock $\mathrm{A}$. Motor recovery after stroke: a systematic review. Lancet Neurol 2009;8:741-54.

48. Takeuchi N, Izumi S. Rehabilitation with poststroke motor recovery: a review with a focus on neural plasticity. Stroke Res Treat 2013;2013:128641.

49. French B, Thomas LH, Leathley MJ, et al. Repetitive task training for improving functional ability after stroke. Cochrane Database Syst Rev 2007;(4):CD006073.

50. Brogardh C, Flansbjer UB, Lexell J. Self-reported walking ability in persons with chronic stroke and the relationship with gait performance tests. PM R 2012;4:734-8.

51. Kwakkel G, Kollen B, Lindeman E. Understanding the pattern of functional recovery after stroke: facts and theories. Restor Neurol Neurosci 2004;22:281-99.

52. Langhorne P, Bernhardt J, Kwakkel G. Stroke rehabilitation. Lancet 2011;377:1693-702. 